\title{
Platelet Count/Spleen Diameter Ratio as a Predictor of Esophageal Varices in Patients with Liver Cirrhosis
}

\author{
Khadka $D^{1}, K C S^{2}$, Khadka $S^{3}$ Regmi $K^{4}, K C P^{5}$
}

\begin{abstract}
Introduction: Upper gastro-intestinal endoscopy still remains the gold standard for screening of patients suspected to have esophageal varices but not without limitations. So, this study was conducted to access the diagnostic validity and correlation between non-invasive parameters like platelet count, spleen diameter and their ratio with esophageal varices (EV) in patients with liver cirrhosis. Methods: A hospital based descriptive cross-sectional study was carried out in Liver unit of National Academy of Medical Sciences, Bir Hospital, from October 2016 to September 2017. Complete blood count, liver function tests, liver ultrasound and UGI endoscopy were done for all patients included in the study to detect esophageal varices and the platelet count/spleen diameter (PC/SD) ratio was calculated and analyzed to determine whether it can predict the presence of esophageal varices or not. Results: Total patients of liver cirrhosis studied after exclusion were 191. EV was present in 125 patients (65.4\%). The platelet count/spleen diameter ratio using a cutoff value of $\leq 909$ to detect EV independent of the grade had $93 \%$ sensitivity and $100 \%$ specificity and positive and negative predictive values of $100 \%$ and $91 \%$ respectively. Conclusions: PC/SD ratio now can be used as a predictor of presence of esophageal varices in liver cirrhosis.
\end{abstract}

Key words: Esophageal varices, liver cirrhosis, non-invasive markers, portal hypertension, upper gastro-intestinal

\section{INTRODUCTION}

Cirrhosis is the end stage of every chronic liver disease characterized by fibrosis and the replacement of normal liver architectures into structurally abnormal nodules which interferes with liver function and results in portal hypertension. Portal hypertension ${ }^{1}$ as a consequence of cirrhosis leads to the formation of esophageal varices (EV) and bleeding $\mathrm{EV}$ is one of the major and often lethal complication ${ }^{2}$.

Upper Gastro-intestinal (UGI) endoscopy still remains the gold standard for screening and diagnosing EV, but it has its own limitation like, it is invasive procedure, expensive and needs expertise too, which may be not available in all hospital settings at all times. Therefore, the present study was undertaken to find the correlation between platelet count, spleen diameter and its ratio with presence of esophageal varices in patients with liver cirrhosis which was simple, quick and reproducible so that unnecessary UGI endoscopy can be limited.

\section{MATERIAL AND METHODS}

This hospital based descriptive cross-sectional study was

1. Dr. Dipendra Khadka

2. Dr. Sudhamshu KC

3. Dr. Sandip Khadka

4. Dr. Kiran Regmi

5. Dr. Pooja KC

Address for correspondence:

Dr. Dipendra Khadka

Department of Medicine

Nepalgunj Medical College \& Teaching Hospital

Kohalpur, Banke, Nepal

Email: khadkadipendra39@gmail.com carried out in Liver unit of National Academy of Medical Sciences, Bir Hospital, Nepal from October 2016 to September 2017. Patients attending Liver unit on outdoor basis and or admitted in ward were enrolled in the study who fulfilled the criteria of liver cirrhosis, namely, one clinical sign of hepatocellular failure and one of portal hypertension along with at least three ultrasonography (USG) findings suggestive of cirrhosis of liver ${ }^{3}$. The following cases with cirrhosis with portal hypertension were excluded from the study: Those patients presenting with variceal bleed or past history of bleeding, patient who had undergone band ligation, patient with hepatocellular carcinoma, cirrhosis with portal vein thrombosis, patient in hepatic encephalopathy grade III or IV and patient refusing for consent.

A detailed history as well as clinical examination was done. Complete blood count was done by automated cell counter, Sysmex 550. Peripheral blood smear was done to rule any other hematological cause of thrombocytopenia. Liver function test was done by Erba XL 300, automated analyzer. Prothrombin time and international normalized ratio was also calculated. All the blood investigations were duly verified by pathologist. All patients underwent 2D ultrasound study of hepatobiliary system for liver architecture and nodularity, spleen bipolar diameter, presence of ascites by Sonosite Micromax doppler ultrasound. UGI endoscopy for all patients was done after overnight fasting with flexible gastroduodenal endoscope (FUIINON). EV were classified as small if varices flattened with insufflations or minimally protrude into the esophageal lumen and large if they protruded into the esophageal lumen and touch each other (presence of confluence), or that filled at least $50 \%$ of the esophageal lumen ${ }^{4}$. Child-Turcotte-Pugh (CTP) score was calculated to assess the severity of liver disease ${ }^{5}$. The 
Platelet count/Spleen diameter ratio (PC/SD) cut off value 909, proposed by Giannini et al, is among the best non-invasive predictor of EVs that has been studied till date was taken for reference ${ }^{6}$. Ethical approval was taken from Institutional Review Board (IRB), NAMS and written informed consent was taken from each patient.

Sample size was calculated by following formula:

$$
n=4\left[\frac{z_{\frac{\alpha}{2}}+z_{\beta}}{\ln \frac{(1+\rho)}{(1-\rho)}}\right]^{2}+3
$$

Assuming small effect size of 0.2 at $5 \%$ significance level with $z_{\alpha}=1.96$, with $80 \%$ power with $z_{\beta}=0.84$, using formula minimum sample size was 191. Data collected in structured proforma were entered in Microsoft Excel 2007 and statistical analysis was done with SPSS 20 software. Chi-Square test was used for comparisons between categorical variables. Values were expressed as mean $\pm S D$, a $95 \%$ confidence interval was taken and $P$ values of $<0.05$ was considered to be statistically significant.

\section{RESULTS}

Total patients enrolled in the study were 350, among them 159 were excluded and finally 191 patients were studied. During
UGI endoscopy, EV was present in 125 patients (65.4\%). Significant relation between CTP class and presence of varices was observed (Chi sq. test statistic $=84.808 ; P=<0.001$ ). Varices were present in majority of cases with CTP class C (Table I).

Platelet count and spleen diameter and their ratio (PC/SD) were calculated as a non-invasive tool for predictor of EV. Significant relation was observed as shown in table II.

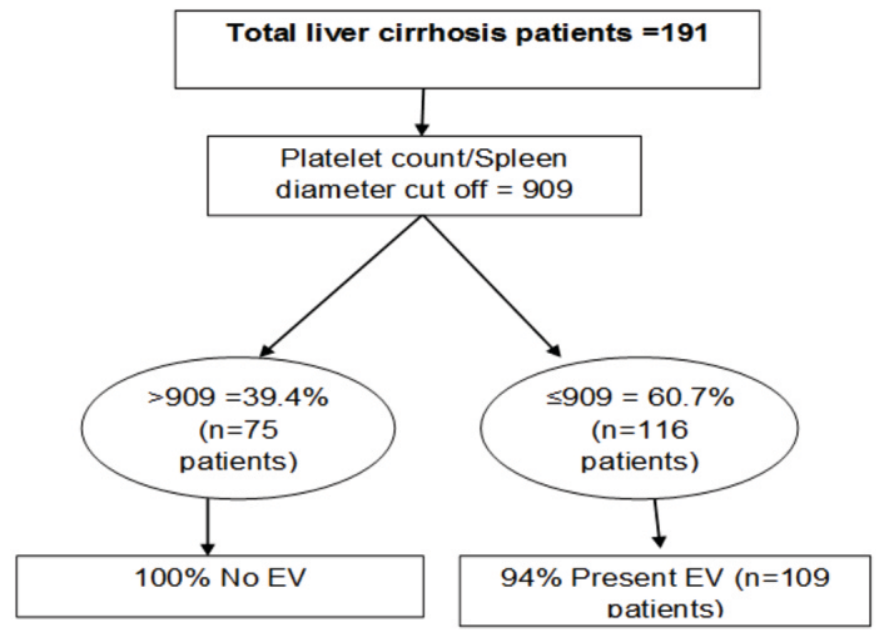

Figure 1: Flow chart showing absence of EV in $100 \%$ cases with $\mathrm{PC} / \mathrm{SD}$ ratio $>909$

\begin{tabular}{|c|c|c|c|c|c|}
\hline CTP Class & NEV & EV & Total & Chi-Square & \\
\cline { 1 - 4 } A & 4 & 6 & 10 & \multirow{2}{*}{84.808} \\
B & 40 & 57 & 97 & 80.001 \\
\cline { 1 - 4 } C & 22 & 62 & 194 & \\
\hline
\end{tabular}

$\mathrm{NEV}=$ No Esophageal varices, $\mathrm{EV}=$ Esophageal varices

Table I: Relation between CTP classes and EV

\begin{tabular}{|l|c|c|c|c|}
\hline Variable & Mean & SD & EV & P value \\
\hline Platelet $\left(\mathrm{n} / \mathrm{mm}^{3}\right)$ & 83660.34 & 31066.45 & Yes & No \\
\hline & 230528.00 & 210465.76 & Yes & $<0.0001$ \\
\hline Spleen size $(\mathrm{mm})$ & 143.66 & 10.85 & No & $<0.0001$ \\
\hline PC/SD ratio & 131.19 & 16.676 & Yes & $<0.0001$ \\
\hline
\end{tabular}

$\mathrm{EV}=$ Esophageal varices

Table II: Relationship between Platelet count and Spleen diameter and PC/SD ratio with EV

\begin{tabular}{|l|c|c|c|c|}
\hline $\begin{array}{l}\text { PC/SD Ratio } \\
\text { Cut off value }\end{array}$ & Sensitivity & Specificity & $\begin{array}{c}\text { Positive } \\
\text { predictive value }\end{array}$ & $\begin{array}{c}\text { Negative } \\
\text { predictive value }\end{array}$ \\
\hline$\leq 909$ & $93 \%$ & $100 \%$ & $100 \%$ & $91 \%$ \\
\hline
\end{tabular}

Table III: PC/SD ratio $\leq 909$ have $93 \%$ sensitivity and $100 \%$ specificity having EV with PPV $100 \%$ and NPV $91 \%$ as shown below 


\section{DISCUSSION}

Varices usually develop in cirrhosis when portal pressure, measured as hepatic venous pressure gradient (HVPG) reached up to $10-12 \mathrm{mmHg}^{1}$. Once varices develop, rate of enlargement from small to large is at a rate of $5-12 \%$ per year and bleed at a rate of $5-15 \%$ per year ${ }^{7}$. Early diagnosis of varices before the first bleed is essential because the risk of variceal hemorrhage can be reduced from $50 \%$ to about $15 \%$ for large esophageal varices if timely primary prophylaxis initiated timely. UGI endoscopy remains the gold standard for screening, but this test is not without its own limitations. To overcome this problem some non-invasive parameters have been developed like platelet count, spleen size and ratio PC/SD which are simple, quick, reproducible, and cost effective too.

In our study, majority of patients with EV were in CTP class C $(P=<0.0001)$. Garcia-Tsao et al, also reported EV were more common in CTP class C (85\%) as compared to class A $(40 \%)^{1}$. As liver disease severity score reflected by CTP class, higher the score, more the disease severity and thus more the incidence of EV.

In this study, mean platelet count of $83660.34 \pm 31066.45 / \mathrm{mm}^{3}$ was associated with presence of $\mathrm{EV}$ and with no $\mathrm{EV}$ group it was $230528 \pm 210465.76 / \mathrm{mm}^{3}(\mathrm{P}=<0.0001)$. Chalasani et al, in their study also reported low platelet count $\left(<88,000 / \mathrm{mm}^{3}\right)$ as an independent predictor of $\mathrm{EV}^{9}$. Thomopoulos et al, observed platelet count of $<118,000 / \mathrm{mm}^{3}$ as a predictor for presence of EV with sensitivity of $95 \%$ and specificity of $73 \%{ }^{10}$.

In our study showed that average spleen size in patients without EV was $131.19 \pm 16.67 \mathrm{~mm}$ and with varices was $143.66 \pm 10.85 \mathrm{~mm} \quad(P=<0.0001)$. Thomopoulos et al, also reported splenomegaly (>135 $\mathrm{mm}$ ) as a predictor of $\mathrm{EV}^{10}$. In the study by Agha et al, the mean spleen diameter of EV group was $147 \mathrm{~mm}$ and no EV group was $109 \mathrm{~mm}^{11}$. Splenomegaly in cirrhosis is mainly related to development of portal hypertension as a consequence of cirrhosis.

In our study PC/SD ratio $579 \pm 201$ was associated with $\mathrm{EV}$ and ratio of $1817 \pm 1792$ was not associated with $\mathrm{EV}$ which is also statistically significant $(P=<0.0001)$. Compare to Giannini et al, platelet count/spleen diameter ratio 1638 (545-3500) was not associated with EV and 533 (77-909) was associated with EV $(P=<0.0001)$ with cut off value of 909 in their study with sensitivity of $100 \%$ and specificity of $93 \%$ and positive predictive value of $96 \%$ and negative predictive value of $100^{6}$. Comparable results were obtained in our study too with sensitivity of $93 \%$ and specificity of $100 \%$ and positive and negative predictive value of $100 \%$ and $91 \%$ respectively. Tiwari et al reported the sensitivity and specificity keeping the PC/SD ratio cut-off 909, the values obtained were, sensitivity and specificity of $81.8 \%$ and $100 \%$, respectively, the positive and negative predictive values for PC/SD ratio were $100 \%$ and
$73.91 \%$, respectively which were comparable to our study too ${ }^{12}$. With similar cutoff value of PC/SD Chawla et al, also demonstrate a diagnostic accuracy of cut-off 909 for PC/SD ratio as a predictor of $\mathrm{EV}^{13}$. González-Ojeda A et al, demonstrate $\mathrm{PC} / \mathrm{SD}$ ratio $824.56 \pm 412.27$ was related to $\mathrm{EV}$ and ratio of $1390 \pm 905.49$ was not related to presence of $\mathrm{EV}(0.018)^{14}$.

Limitation of our study was measurement of portal pressure as hepatic venous pressure gradient (HVPG) was not done in our study. Diagnostic accuracy of PC/SD ratio as a predictor of EV may be further validated by multicenter study.

\section{CONCLUSIONS.}

The $\mathrm{PC} / \mathrm{SD}$ ratio can be a useful noninvasive predictor for esophageal varices in patients with liver cirrhosis and thereby may help reducing the number of unnecessary endoscopies.

\section{ACKNOWLEDEMENT}

I would like to thank Mr. Tarka Bahdadu Malla and Mr. Sangram Chaudhary for kind support during statistical analysis.

\section{REFERENCES}

1. Garcia-Tsao G, Sanyal AJ, Grace ND, Carey W. Prevention and management of gastroesophageal varices and variceal hemorrhage in cirrhosis. Hepatology. 2007 Sep 1;46(3):922-38.

2. D'Amico G, Luca A. Natural history. Clinical-haemodynamic correlations. Prediction of the risk of bleeding. Baillieres Clin Gastroenterol. 1997 Jun 1;11(2):243-56.

3. Syed VA, Ansari JA, Karki P, Regmi M, Khanal B. Spontaneous bacterial peritonitis (SBP) in cirrhotic ascites: a prospective study in a tertiary care hospital, Nepal. Kathmandu Univ Med J (KUMJ). 2007;5(17) :48-59.

4. De Franchis R, Pascal JP, Ancona E, Burroughs AK, Henderson M, Fleig $W$ et al. Definitions, methodology and therapeutic strategies in portal hypertension: a Consensus Development Workshop, Baveno, Lake Maggiore, Italy, April 5 and 6, 1990. J Hepatol. 1992 May 1;15(1-2):256-61.

5. Hong SH, Kim JE, Cho ML, Heo YJ, Choi JH, Choi JH et al. Comparison of the Child-Turcotte-Pugh classification and the model for end-stage liver disease score as predictors of the severity of the systemic inflammatory response in patients undergoing living-donor liver transplantation. J Korean Med Sci. 2011 Oct 1;26(10):1333-38.

6. Giannini E, Botta F, Borro P, Risso D, Romagnoli P, A Fasoli A et al. Platelet count/spleen diameter ratio: proposal and validation of a non-invasive parameter to predict the presence of oesophageal varices in patients with liver cirrhosis Gut 2003;52:1200-05.

7. Merli M, Nicolini G, Angeloni S, Rinaldi V, De Santis A, Merkel C et al. Incidence and natural history of small esophageal varices in cirrhotic patients. J Hepatol. 2003 Mar 31;38(3):266-72.

8. D'Amico G, Pagliaro L, Bosch J, Patch D. "Pharmacological treatment of portal hypertension: an evidence-based approach," Semin Liver Dis. 1999;19(4):475-505.

9. Chalasani N, Imperiale TF, Ismail A, Sood G, Carey M, Wilcox CM et al. Predictors of large esophageal varices in patients with cirrhosis. Am J Gastroenterol. 1999 Nov 1;94(11):3285-91.

10. Thomopoulos KC, Labropoulou-Karatza C, Mimidis KP, Katsakoulis EC, Iconomou G, Nikolopoulou VN. Non-invasive predictors of the 
presence of large oesophageal varices in patients with cirrhosis. Dig Liver Dis. 2003 Jul 31;35(7):473-78.

11. Agha A, Anwar E, Bashir K, Savarino V, Giannini EG. External validation of the platelet count/spleen diameter ratio for the diagnosis of esophageal varices in hepatitis $\mathrm{C}$ virus-related cirrhosis. Dig Dis Sci. 2009 Mar 1;54(3):654-60.

12. Tiwari D, Kumar S, Lahariya D, Jacob J.Comparison between Platelet Count, Spleen Diameter and Their Ratio with Esophageal Varices in Patients with Liver Cirrhosis. American Journal of Medicine and Medical Sciences 2016 6(1): 29-33.

13. Chawla S, Katz A, Attar BM, Gupta A, Sandhu DS, Agarwal R. Platelet count/spleen diameter ratio to predict the presence of esophageal varices in patients with cirrhosis: a systematic review. Eur J Gastroenterol Hepatol 2012; 24: 431-6.

14. González-Ojeda A, Cervantes-Guevara G, Chávez-Sánchez M, Dávalos-Cobián C, Ornelas-Cázares S, Macías-Amezcua MD et al. Platelet count/spleen diameter ratio to predict esophageal varices in Mexican patients with hepatic cirrhosis .World J Gastroenterol 2014 February 28; 20(8): 2079-84. 